\title{
Search Rate and Functional Response of a Eusocial Insect (Oecophylla longinoda) in a Tanzanian Mango Orchard
}

\author{
Thora Samsø Fast, ${ }^{1}$ Jørgen Aagaard Axelsen,, Gina Kier Lynegaard, 1 \\ Maulid Mwatawala, ${ }^{2}$ and Joachim Offenberg ${ }^{1}$ \\ ${ }^{1}$ Department of Bioscience, Aarhus University, 8000 Aarhus C, Denmark \\ ${ }^{2}$ Department of Crop Science and Production, Sokoine University of Agriculture, Morogoro, Tanzania \\ Correspondence should be addressed to Jørgen Aagaard Axelsen; jaa@bios.au.dk
}

Received 28 December 2014; Revised 13 February 2015; Accepted 16 February 2015

Academic Editor: Jan Klimaszewski

Copyright ( $\odot 2015$ Thora Samsø Fast et al. This is an open access article distributed under the Creative Commons Attribution License, which permits unrestricted use, distribution, and reproduction in any medium, provided the original work is properly cited.

\begin{abstract}
Weaver ants, Oecophylla spp., are famous for being efficient biological control agents as they prey on a variety of insects, and they are capable of suppressing a large number of pest species. Here, the search rate and functional response of Oecophylla longinoda were investigated in a Tanzanian mango orchard using feeding experiments. This was done by following the removal of prey, which constituted the foundation for estimating the search rate by aid of the Nicholson-Bailey and Lotka-Volterra models. The overall mean search rate was $3.2 \times 10^{-4}$ and $1.7 \times 10^{-4}$ over 30 minutes, when calculating the search rate using the Nicholson-Bailey equation and the Lotka-Volterra equation (modified Holling equation), respectively. The functional response investigations showed a linear relationship between removed prey and available prey, suggesting type I functional response or, alternatively, the initial phase of type II functional response. The results presented here are probably the first attempt to identify the functional response type of a colony of living predatory eusocial insects.
\end{abstract}

\section{Introduction}

Biocontrol using weaver ants, Oecophylla spp., has successfully been carried out throughout Asia, Australia $[1,2]$, and, to some extent, Africa [3, 4]. Oecophylla spp. live in colonies in trees where a colony may consist of more than 100 nests and cover many trees, and the two known species have been shown to be beneficial for farmers in multiple ways. Firstly, the ants are generalist predators and control several pest species in a variety of crops such as mango, cashew, coconut, coffee, and mahogany $[5,6]$. Using ants as a biological control agent has been shown to increase fruit yield in several crops and may also reduce pesticide costs. For instance, using ants while applying soft chemicals as an integrated pest management strategy in a mango orchard in Darwin, Australia, saved AUD 0.25 /tree per year and increased average profit by $73 \%$ in comparison to using chemical pesticides [7]. Secondly, these ants are edible and can be harvested and may serve as a protein source for humans or livestock $[8,9]$. Thirdly, the anal spots deposited by the ants contain nutrients, which may be absorbed by the plants and potentially contribute to plant growth [10]. Thus, weaver ants have often proved to be effective biocontrol agents and may furthermore serve as an alternative source of food and fertilizer.

Several factors influence the efficiency of ants as biocontrol agents. Among these are ant densities [11, 12], size and age of colony [13], crop species [6,14], and climatic conditions [15]. Furthermore, pest dynamics can be affected by predatorprey interactions, involving, for instance, the predator's ability to search for and kill prey. The search rate is a measure of the rate at which the predator encounters prey [16] and for ants may depend on sugar availability [17]. The search rate is an important element in predator-prey interactions and has been included in many mathematical descriptions of predator-prey dynamics such as Holling's disc equation, the simple Lotka-Volterra equations, the Nicholson-Bailey equation, and the Gutierrez-Baumgärtner equation. The latter equation has often been used in simulation models of predator-prey dynamics, as it is built on a representative and 
realistic biological basis and because independent field data on predator-prey dynamics can be simulated when applying the equation in simulation models $[16,18,19]$. However, it does not seem to be readily applicable to eusocial insect colonies in cases where it is not possible to estimate the demand for reserves, which is an obligatory element in estimating the total colony demand [16]. Therefore, in this study we used both the Lotka-Volterra equation (produces type I functional response) and the Nicholson-Bailey equation (produces type II functional response) to calculate the search rate, as it is not clear which functional response type is most suitable to describe the predatory behaviour of an ant colony.

The functional response describes foraging capacity and is defined as the amount of the prey consumed as a function of prey density during a certain period of time. There are basically three kinds of functional response types each having a characteristic curve. Type I functional response curve increases linearly where the predator has an increasing rate of prey intake and is produced by the simple Lotka-Volterra equation. This type of functional response is, for instance, representative for spiders waiting passively in their webs until prey is caught [20]. Type II functional response curve increases similarly to type I response curve but decelerates into an upper asymptote at high prey densities as the predator reaches satiation. Most insects follow type II functional response [21] and this type is generally the most common one [22]. The Nicholson-Baily equation produces type II response. Type III functional response curve has a sigmoid shape and encompasses density dependence where preyswitching occurs at low prey densities. At low prey densities, learning may also occur, which is the ability to achieve a faster handling time with increasing prey density. Type III functional responses are relatively rare for arthropods but have been shown for certain flies, beetles, hemipterans, and lower crustaceans [23-25]. Jeschke et al. [22] have reviewed 48 different functional response equations and by far most of them include handling time and/or predator satiation, and a few of them are even of a dome shaped type IV or have other shapes.

Search rates and functional responses have mainly been investigated for solitary insects of which the foraging activity reflects the demand for prey of an individual. Eusocial insects, on the other hand, forage to fulfil the entire colony's demand for prey, and the colony reproduces as a single unit [26]. In this study, field data were used to investigate (i) the search rate of $O$. longinoda workers in mango trees and (ii) the functional response of $O$. longinoda colonies under natural conditions.

\section{Materials and Methods}

2.1. The Field Site. The study was conducted in January 2012 on 45, 6-year-old mango (Mangifera indica, variety: apple) trees. The spacing between trees was $6 \times 6$ meters and the trees were 2.5-3.0 meters high. The study was carried out in the Kibaha district, Coast Region (Pwani), Tanzania $\left(6^{\circ} 44^{\prime} 3^{\prime \prime} \mathrm{S}\right.$, $38^{\circ} 43^{\prime} 53^{\prime \prime} \mathrm{E}$ ). The entire study was conducted during the short rainy season with daily temperatures (7 AM-7 PM) ranging between 26.8 and $30.3^{\circ} \mathrm{C}$ and an average temperature of $29.0^{\circ} \mathrm{C}$ (weather data from Dar Es Salaam Airport).
2.2. Establishment of Weaver Ant Colonies. O. longinoda colonies were transplanted to the experimental trees one month before the study was initiated. Colonies were collected from a nearby citrus orchard by cutting down the available nests by aid of a clipping pole. The nests were rapidly put into plastic bags and brought to the experimental orchard where they were placed in the crown of an experimental tree and torn open to let the ants colonize the tree. All nests from a colony in the citrus plantation were placed in the same experimental tree. The queen's nest was carefully identified from each colony in the citrus plantation and transferred with the other nests from the colony to secure a normal functioning of the transplanted colonies. The transplanted colonies were allowed to colonize six to twelve trees depending on the size of the transplanted colony (number of nests) and the trees were connected by ropes ( $4 \mathrm{~mm}$ in diameter) to facilitate the "traffic" between trees of a colony. After transplantation the colonies were fed with about $10 \mathrm{~mL}$. $20 \%$ sugar solution (in test tubes attached to the tree) and about $10 \mathrm{~g}$. cat food (placed on the upper side of the main branches) once to boost colony establishment and growth. The trees were pruned to avoid contact between neighbouring colonies.

2.3. Worker Numbers and Densities. Worker ant densities were assessed prior to each experiment by aid of the Forager Density Index (FDI) [9] described in

$$
\mathrm{FDI}=\frac{((1 / 3) L+(2 / 3) \mathrm{Me}+H)}{T},
$$

where $L, \mathrm{Me}$, and $H$ were the number of main branches having low, medium, and high densities of ants and $T$ was the total number of main branches. Main branches with low, medium, or high densities of ants were defined as branches having 1-9 ants, 10-50 ants, or $>50$ ants, respectively. Branches without ants did not count in the index but were included in $T$.

A relatively high ant activity was required to ensure that experiments reflected situations with good biocontrol, and therefore only trees with FDI $\geq 0.5$ were used in the experiments.

Nest width and length were accurately measured for all nests in all trees using a folding ruler, and the measurements were used to estimate ant numbers based on the equations from Lim [27].

2.4. Field Experiments. Nine ant colonies distributed on 13 trees in total were used to investigate the search rate. Five pieces of $1.5 \times 5.0 \mathrm{~cm}$ double-sided adhesive tape were pasted haphazardly on the branches (up to two meters height) of each of the nine trees used in the experiments. Tape pieces were never pasted onto branches that had a diameter less than $3 \mathrm{~cm}$. Each piece of tape had 10 equally sized insect prey items, which were evenly distributed, pasted onto it (Figure 1). Prey types included individuals from the orders Lepidoptera, Hemiptera, and Diptera. Prey items were not replaced when removed by the ants, which means the prey density declined with time. 
TABLE 1: Average dry-weight (mg) of individual prey items used in experiment.

\begin{tabular}{lccccc}
\hline Order & Diptera (Culicidae) & Lepidoptera & Hemiptera & Diptera (Musca domestica) & Mixed prey types \\
\hline Average dry-weight $(\mathrm{mg})$ & 0.10 & 0.89 & 7.62 & 5.06 & 4.52 \\
\hline
\end{tabular}

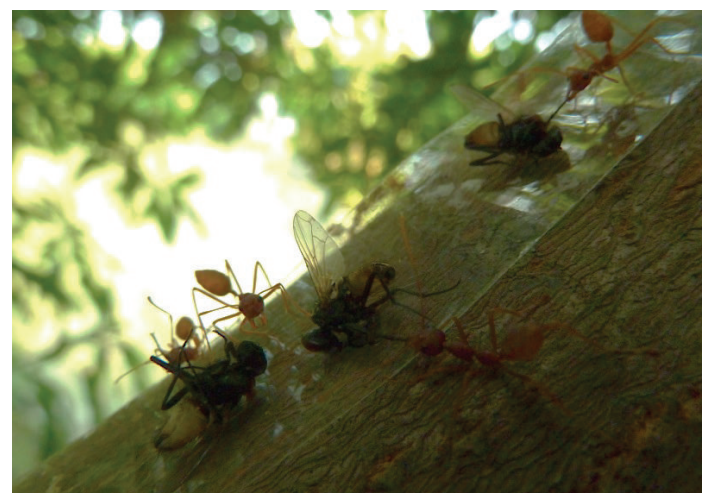

FIGURE 1: Oecophylla longinoda removing prey from tape pieces.

In order to estimate the biomass of the prey provided in the experiments, samples of at least 18 individuals of each prey type were collected in the field, dried for $24 \mathrm{hrs}$ at $60^{\circ} \mathrm{C}$, and weighed, and the average biomass was calculated. In cases with pieces of tape comprising a mix of prey types, an average biomass was estimated from the average biomasses of the used prey types (Lepidoptera, Hemiptera, and house flies (Musca domestica)) (Table 1).

In an experiment five pieces of tape (each with 10 prey items) were pasted in each tree, and every 30 minutes the number of preys left on the tapes was counted. When all prey had either disappeared or 150 minutes had passed, the ongoing experiment was ended. The search rate was calculated for each time interval.

As other predators or wind might also cause prey removal, background disappearance rate was measured in 5 control trees in which ants were not present.

The functional response of $O$. longinoda was investigated for 13 ant colonies distributed on a total of 29 trees. Each tree had the same experimental set-up as used to investigate the search rate; however, prey numbers per tree ranged from 10 to 200 , that, is $1-20$ pieces of tape with 10 prey items each. The only prey type in this experiment was (Musca domestica) having an average dry-weight of $5.06 \mathrm{mg}$. The experiment was stopped after 30 minutes when the numbers of prey left on the tapes were counted.

2.5. Data Treatment. The search rates were initially estimated using a modified version of Holling's disc equation [28], which reduces to a Lotka-Volterra equation (representing type I) when handling time can be ignored. Ignoring handling time seems acceptable in the case of an ant colony because even when a large group of ants is handling a larger prey, there will normally still be immense numbers of other ants searching for prey. Ignoring the handling time in Holling's disc equation reduced it to

$$
s(\Delta \mathbf{t})=\frac{M^{*}}{N_{w} \cdot M^{\prime}},
$$

where $s(\Delta \mathbf{t})$ is the ants' search rate in the time interval $\Delta \mathbf{t}$, $M^{*}$ is the food acquired by the predator measured as the amount that disappears during the experiment, $M^{\prime}$ is the available biomass of prey, and $N_{w}$ is the number of workers. Another functional response equation, which represents type II response, is the Nicholson-Bailey equation [29]

$$
\begin{aligned}
M^{*} & =M^{\prime} \times\left(1-\mathrm{e}^{-\mathbf{s}(\Delta t) \times \mathbf{N}_{\mathrm{w}}}\right) \\
& \Longleftrightarrow \mathrm{s}(\Delta \mathrm{t})=\frac{-\ln \left(1-\mathbf{M}^{*} / \mathbf{M}^{\prime}\right)}{\mathbf{N}_{\mathrm{w}}} .
\end{aligned}
$$

This equation is independent of both demand rate and handling time and assumes that predators are searching randomly, which means that a group of predators (such as the workers from an ant colony) may search overlapping areas. These two equations, (2) and (3), seem to be good candidates to describe the functional response of a colony of predatory eusocial insects while most other functional response equations reviewed by Jeschke et al. [22] do not seem to be applicable as they have handling time and satiation as key parameters, parameters that are either difficult to estimate at colony level (satiation) or seem to be irrelevant (handling time) due to the large number of searching workers although some individuals are busy handling preys.

The total number of workers in (3) was estimated by correlating to nest size, using the equation by Lim [27]:

$$
\ln N_{\text {ants }}=-1.16+1.09 \ln V \text {, }
$$

where $V$ is the volume of a nest calculated by

$$
V=2 \times l \times r \times \pi,
$$

where $r$ is the nest radius in $\mathrm{cm}(=(1 / 2)$ height $)$ and $l$ is the length of the nest in $\mathrm{cm}$.

2.6. Statistical Treatment. The search rate was tested for dependence on colony, colony size, tree crown volume, and time interval by aid of one-way analyses of variance (ANOVA). Similarly, concerning the functional response the dependence of the amount of removed prey on the amount of prey available was tested by aid of ANOVA, and the fits of data to functional response types were investigated by comparing $R^{2}$-values of linear and logarithmic trend lines. 
TABLE 2: Cumulated percentage prey detection after $t=0$ and the cumulated background disappearance rate.

\begin{tabular}{lcccc}
\hline Interval (min) & $0-30$ & $30-60$ & $60-90$ & $90-120$ \\
\hline $\begin{array}{l}\text { Percentage of tape pieces } \\
\text { discovered after } t=0\end{array}$ & 77 & 91 & 100 & 100 \\
$\begin{array}{l}\text { Background disappearance } \\
\text { rate }(\%)\end{array}$ & 0 & 1.76 & 1.76 & 2.35 \\
\hline
\end{tabular}

\section{Results}

3.1. Field Observations: Background Disappearance Rate. It was observed that $O$. longinoda removed and carried preys from tape pieces to their nests, ensuring that data reflects ant activity and that preys were not removed by, for example, wind or other animals. In all experiments, ants detected prey on at least one piece of tape within the first time interval. Background disappearance rate ranged between 0 and $2.35 \%$ of the mass of prey items depending on the time interval and was subtracted from the removed biomass before data treatment (Table 2).

3.2. Field Observations: Prey Removals. The total amount of prey that disappeared from the tapes $\left(M^{*}\right)$ measured in $\mathrm{mg}$ dry-weight per colony during the 30-minute time intervals is summarised in Table 3 . Biomass of prey provided $\left(M^{\prime}\right)$ at $t=$ 0 varied according to prey type; therefore the percentage of prey removal within a given time interval is also summarised. The time interval prey removal rates varied between 0 and $100 \%$ and showed no tendency to decrease or increase with time.

3.3. Search Rate. An average search rate for each time interval was calculated for all colonies (Table 4), and the search rate was not significantly dependent on the time interval regardless of which equation was used to calculate the search rate (ANOVA, d.f. $=4, F=0.32$, and $P=0.86$ using LotkaVolterra and d.f. $=4, F=2.26$, and $P=0.08$ using NicholsonBailey). Instead, the search rate was significantly different between colonies when using Lotka-Volterra (ANOVA, d.f. $=8, F=6.34$, and $P=0.001$ ) but not significantly different between colonies using Nicholson-Bailey (ANOVA, d.f. $=8$, $F=1.70$, and $P=0.13$ using Nicholson-Bailey). The overall mean search rate was $3.2 \times 10^{-4}$ and $1.7 \times 10^{-4}$ over $30 \mathrm{~min}-$ utes when calculating the search rate using the NicholsonBailey equation and the Lotka-Volterra equation (modified Holling equation), respectively. The search rate comes in units of time $e^{-1}$, and therefore it makes sense to convert the search rate to units of hour ${ }^{-1}$ giving an average search rate of $6.4 \times 10^{-4}$ ant $^{-1} \times$ hour $^{-1}$ and $3.4 \times 10^{-4}$ ant $^{-1} \times$ hour $^{-1}$ using the two equations, respectively. There is a rather large variation in search rates between the colonies, from $0.9 \times 10^{-4}$ to $10.9 \times 10^{-4}$ using the Nicholson-Bailey equation and from $0.8 \times 10^{-4}$ ant $^{-1} \times$ hour $^{-1}$ to $5.7 \times 10^{-4}$ ant $^{-1} \times$ hour $^{-1}$ using the Lotka-Volterra equation. There was no significant dependency between search rate and colony size (ANOVA, d.f. = $1,42, F=2.68$, and $P=0.11$ using Lotka-Volterra and $F=0.16, P=0.69$ using Nicholson-Bailey) or between

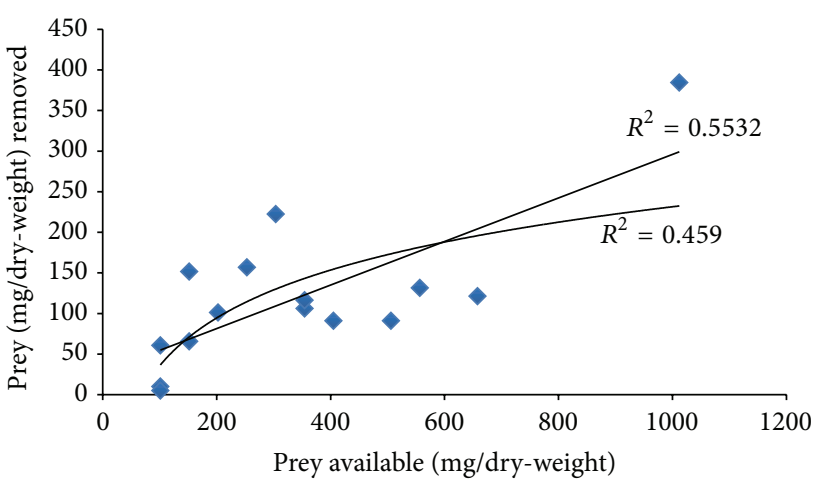

FIGURE 2: Linear and logarithmic trend lines representing type I and type II functional response functions, respectively, compared to observed data.

search rate and tree crown volume (ANOVA, d.f. $=1,42$, $F=0.94$, and $P=0.0 .34$ using Lotka-Volterra and $F=0.27$, $P=0.61$ using Nicholson-Bailey).

3.4. Functional Response. The amount of prey removed was significantly dependent on the amount of prey available relationship (ANOVA: d.f. $=1, F=16.10$, and $P=0.002$ ), and a linear trend line showed larger $R^{2}$-value $(0.55)$ than a logarithmic trend line (0.46) (Figure 2). This result indicates type I functional response or, alternatively, the initial part of type II that has not reached satiation. Similar analyses were also carried out expressing the removed prey in units of "prey removed per worker (g prey/worker)" and "prey removed per worker per tree crown volume" (g prey/worker $/ \mathrm{m}^{3}$ ), but the $R^{2}$-values were clearly lower $\left(0.24\right.$ and $8 \times 10^{-3}$, resp.). Furthermore, the significant dependence of the amount of removed prey on the amount of available prey disappeared when using these units (ANOVA: d.f. $=1,14, F=3.75$, and $P=0.08$ (g prey/worker) and d.f. $=1,14, F=0.10$, and $P=0.75\left(\right.$ g prey/worker $\left.\left./ \mathrm{m}^{3}\right)\right)$.

\section{Discussion}

4.1. Functional Response. When investigating the functional response of $O$. longinoda, a linear relationship revealed the largest $R^{2}$-value (Figure 2 ), and the relationship was significant when neither ant density nor tree crown volume was included. The trend line on the graph indicated no sign of satiation of $O$. longinoda, and therefore the results indicated type I functional response or initiating type II functional response.

Oecophylla spp. and ants in general are known to be opportunistic feeders and aggressive hunters [30]. Workers forage in randomly or slightly clumped distributions, with more foragers out in a starved colony under which conditions cannibalism of brood also occurs [31, 32]. When large prey is detected, chemical cues are used to recruit workers [33, 34 ] and ants are known to bring down large prey including vertebrates such as lizards and birds, of which remains have also been found in dissected Oecophylla nests (J. Offenberg, personal observation; $[34,35])$. 
TABLE 3: Total removed prey $\left(M^{*}\right)$ per tree measured in mg dry-weight and the prey removal rate (\%) within each time interval. The removal rate (5) was based on the amount available at the start of each interval.

\begin{tabular}{|c|c|c|c|c|c|}
\hline \multirow{2}{*}{ Colony } & \multicolumn{5}{|c|}{ Time interval (min) } \\
\hline & $t=0-30$ & $t=30-60$ & $t=60-90$ & $t=90-120$ & $t=120-150$ \\
\hline 1 & $22.1(9.8 \%)$ & $110.5(55.2 \%)$ & $57.4(64.6 \%)$ & $17.7(57.1 \%)$ & $8.8(66.7 \%)$ \\
\hline 2 & $4.4(4.9 \%)$ & 0 & $8.8(10.5 \%)$ & 0 & 0 \\
\hline 3 & $26.5(14.6 \%)$ & $22.1(14.5 \%)$ & $13.3(10.2 \%)$ & 0 & 0 \\
\hline 4 & $44.2(30.6 \%)$ & $14.1(14.5 \%)$ & $13.3(15.9 \%)$ & $23.8(34.2 \%)$ & $7.0(15.3 \%)$ \\
\hline 5 & $153.2(75.7 \%)$ & $14.8(33.1 \%)$ & $19.8(66.3 \%)$ & $4.9(50.0 \%)$ & $4.9(100.0 \%)$ \\
\hline 6 & $9.9(9.8 \%)$ & $29.6(33.1 \%)$ & $4.9(8.3 \%)$ & 0 & $14.8(27.3 \%)$ \\
\hline 7 & $8.4(40.3 \%)$ & $1.4(11.4 \%)$ & 0 & 0 & 0 \\
\hline 8 & $45.0(57.4 \%)$ & $14.9(47.0 \%)$ & $15.0(89.7 \%)$ & $0.1(6.3 \%)$ & 0 \\
\hline 9 & $5.4(18.6 \%)$ & $14.0(61.2 \%)$ & $2.6(29.7 \%)$ & $0.9(14.2 \%)$ & $0.9(16.5 \%)$ \\
\hline
\end{tabular}

TABLE 4: The search rates from the 9 trees calculated according to the Nicholson-Bailey equation (upper line in normal font) and LotkaVolterra (lower lines in italics). All figures are $\times 10^{-4}$ ant $^{-1} \times 30$ minutes $^{-1}$.

\begin{tabular}{|c|c|c|c|c|c|c|c|c|c|}
\hline Colony & Ant density & Crown volume $\left(\mathrm{m}^{3}\right)$ & Int. 1 & Int. 2 & Int. 3 & Int. 4 & Int. 5 & Avg. & S.E. \\
\hline \multirow{2}{*}{1} & \multirow{2}{*}{1216} & \multirow{2}{*}{4.9} & 0.9 & 19.2 & 7.8 & 1.7 & 0.0 & 5.9 & 6.7 \\
\hline & & & 0.8 & 4.8 & 5.0 & 3.7 & 0.41 & 3.7 & 1.8 \\
\hline \multirow{2}{*}{2} & \multirow{2}{*}{346} & \multirow{2}{*}{3.1} & 1.5 & 0.0 & 3.2 & 0.0 & 0.0 & 0.9 & 1.2 \\
\hline & & & 1.4 & 0.0 & 2.9 & 0.0 & 0.0 & 0.9 & 1.1 \\
\hline \multirow{2}{*}{3} & \multirow{2}{*}{687} & \multirow{2}{*}{2.1} & 2.0 & 2.6 & 1.5 & 0.0 & 0.0 & 1.2 & 1.7 \\
\hline & & & 1.7 & 2.1 & 1.3 & 0.0 & 0.0 & 1.0 & 0.6 \\
\hline \multirow{2}{*}{4} & \multirow{2}{*}{2436} & \multirow{2}{*}{3.6} & 1.4 & 1.0 & 1.0 & 1.9 & 0.8 & 1.2 & 1.7 \\
\hline & & & 1.0 & 0.7 & 0.8 & 1.2 & 1.5 & 1.0 & 0.6 \\
\hline \multirow{2}{*}{5} & \multirow{2}{*}{1123} & \multirow{2}{*}{1.4} & 17.1 & 2.7 & 20.5 & 0.0 & & 10.1 & 12.9 \\
\hline & & & 6.7 & 1.8 & 6.4 & 4.5 & 8.9 & 5.7 & 2.1 \\
\hline \multirow{2}{*}{6} & \multirow{2}{*}{1611} & \multirow{2}{*}{2.4} & 0.7 & 4.2 & 2.1 & 0,0 & 1.4 & 1.7 & 1.8 \\
\hline & & & 0.6 & 2.3 & 1.5 & 0.0 & 3.7 & 1.6 & 1.1 \\
\hline \multirow{2}{*}{7} & \multirow{2}{*}{1240} & \multirow{2}{*}{3.6} & 3.7 & 2.3 & 0.0 & 0.0 & 0.0 & 1.2 & 1.4 \\
\hline & & & 2.4 & 1.8 & 0.0 & 0.0 & 0.0 & 0.8 & 0.3 \\
\hline \multirow{2}{*}{8} & \multirow{2}{*}{873} & \multirow{2}{*}{4.0} & 4.6 & 2.6 & 20.0 & 0.9 & 0.0 & 5.6 & 5.1 \\
\hline & & & 3.4 & 1.9 & 4.3 & 0.8 & 0.0 & 2.1 & 1.6 \\
\hline \multirow{2}{*}{9} & \multirow{2}{*}{3014} & \multirow{2}{*}{6.6} & 1.8 & 7.5 & 1.0 & 0.3 & 0.8 & 2.3 & 3.0 \\
\hline & & & 1.0 & 1.8 & 0.7 & 0.3 & 0.6 & 0.9 & 0.5 \\
\hline \multirow{2}{*}{ Avg. } & \multirow{2}{*}{1394} & \multirow{2}{*}{3.5} & 3.8 & 5.5 & 5.7 & 0.5 & 0.3 & 3.2 & \\
\hline & & & 2.1 & 2.1 & 2.3 & 1.0 & 1.2 & 1.7 & \\
\hline \multirow{2}{*}{ S.E. } & \multirow{2}{*}{253} & \multirow{2}{*}{0.5} & 1.1 & 1.8 & 2.4 & 0.3 & 0.2 & 1.1 & \\
\hline & & & 2.5 & 2.6 & 3.0 & 2.3 & 2.6 & 2.6 & \\
\hline
\end{tabular}

Colony maintenance and growth depend on several factors. The brood needs protein for growth and the queen for egg production; workers mainly need sugar for activity and respiration [36]. A surplus of protein may be invested in reproduction of sexuals, thus increasing the fitness of the colony [37]. Only a fraction of the colony is known to forage, and the distribution of prey and other resources within the colony is therefore essential $[15,38]$. When resources are scarce or environmental impacts are unpredictable there is a need for storing existing resources [39]. A study by Rastogi [33] revealed that ants cover large prey with leaves and twigs for hiding. Storage can also be obtained by workers laying trophic eggs $[35,39,40]$ and, in addition, ants are suspected of spraying formic acid on their prey for preservation (J. Offenberg, personal comment). Conservation of prey is an evolutionarily sound approach, especially in the time before the rainy season in which larval production is increased [15]. In small colonies where environmental stochasticity may have a major effect on the survival of a colony, storage of resources may thus have a major effect on colony persistence.

Displaying type I functional response, which does not describe any kind of saturation, may therefore create conditions under which more food than demanded may be acquired, hence improving the chance of survival if a food shortage occurs. This is an ecologically advantageous behaviour and it fits well with the observations made, and 
it suggests using the Lotka-Volterra equation to calculate the functional response in calculating predator-prey relationships. On the other hand, if what we see in our investigation of the functional response is in reality the start of type II functional response, the Nicholson-Baily equation is the obvious choice. As long as this issue has not been settled, it seems reasonable to calculate search rates using equations producing both type I and type II functional response.

Despite a thorough search in literature databases it was not possible to find papers describing attempts to quantify the functional response of ants for comparison. However, by expanding the field to include other eusocial insects such as honey bees and termites we found one paper. Sih and Baltus [41] investigated the functional response of honey bees (Apis mellifera) and bumble bees (Bombus spp.) by relating the patch size with catnip (Nepeta cataria) and in turn the number of available flowers to the visiting frequency of the bees. Their results suggested that the bumble bees showed type I response $\left(R^{2}=0.73\right)$ and the results on honey bees weakly suggested type II response $\left(R^{2}=0.43\right)$. Therefore, the use of type I response to describe prey acquisition by eusocial insects is weakly supported but the evidence is definitely not strong.

Colonies of eusocial insects can be regarded as super [42], and a colony response to increased density of prey at a certain site requires communication within the colony. Eusocial insect colonies are known to have advanced communication systems [42], but there may be a delay between message and response. Satiation of colony demands for sugar and/or prey may take time, and it may also take time until the message that the colony is satiated spreads to all workers. Therefore, investigations of functional response of eusocial insects should probably try to take such a time delay into consideration to get a colony response to increasing resources. Otherwise, type I response will be most likely. In order to demonstrate an accelerating search rate (type III response) the colony should recruit more workers to the resource. This may happen if the resource is dense enough to trigger an aggregated response, and therefore a large resource of relatively scattered preys may cause a weaker response than a resource of the same size concentrated on little space such as dead larger insects or dead vertebrates. The first situation may show type I response, and the second situation may show type III response. Therefore, investigating the functional response of colonies of eusocial insects is much more complicated than investigating the functional response of individual insects.

4.2. Search Rate. The search rate of O. longinoda was found to be dependent on the colony and there is about a factor 10 between the smallest and the largest value. There may be a number of possible reasons for variation in search rate, including state of the colony (young, mature, and old), level of satiation for sugar and/or prey, and season of the year. In this study, we have been using newly established colonies only, which may have reduced the range. However, their original age and demands for prey and sugar remained unknown. Therefore, this study which seems to be one of the first attempts to quantify the search rate and functional response of eusocial insects constitutes a first step, and the results are valid as such. However, in future investigations of the the search rate of $O$. longinoda or other eusocial insects it should be attempted to control the factors causing variation, such as state of colony and demand rate for sugar and/or protein.

\section{Conflict of Interests}

The authors declare that there is no conflict of interests regarding the publication of this paper.

\section{Acknowledgments}

The authors would like to acknowledge Sokoine University of Agriculture (SUA) for granting the permission to conduct the research in the mango orchard in Kibaha, and many thanks are due to Gration Rwegasira, Nassor Rhasid Abdallah, and William George for support and assistance in the field. This work was supported by a grant from Danish Fellowship Center.

\section{References}

[1] J. Offenberg, S. Havanon, S. Aksornkoae, D. J. MacIntosh, and M. G. Nielsen, "Observations on the ecology of weaver ants (Oecophylla smaragdina fabricius) in a thai mangrove ecosystem and their effect on herbivory of Rhizophora mucronata lam," Biotropica, vol. 36, no. 3, pp. 344-351, 2004.

[2] R. Peng, K. Christian, and K. Gibb, "The effect of levels of green ant, Oecophylla smaragdina (F.), colonisation on cashew yield in northern Australia," in Proceedings of the Symposium on Biological Control in the Tropics, pp. 24-28, Selangor, Malaysia, March 1999.

[3] E. A. Dwomoh, J. V. K. Afun, J. B. Ackonor, and V. N. Agene, "Investigations on Oecophylla longinoda (Latreille) (Hymenoptera: Formicidae) as a biocontrol agent in the protection of cashew plantations," Pest Management Science, vol. 65, no. 1, pp. 41-46, 2009.

[4] P. Van Mele, J.-F. Vayssières, E. Van Tellingen, and J. Vrolijks, "Effects of an African weaver ant, Oecophylla longinoda, in controlling mango fruit flies (Diptera: Tephritidae) in Benin," Journal of Economic Entomology, vol. 100, no. 3, pp. 695-701, 2007.

[5] R. K. Peng and K. Christian, "Effective control of Jarvis's fruit fly, Bactrocera jarvisi (Diptera: Tephritidae), by the weaver ant, Oecophylla smaragdina (Hymenoptera: Formicidae), in mango orchards in the Northern Territory of Australia," International Journal of Pest Management, vol. 52, no. 4, pp. 275-282, 2006.

[6] M. J. Way and K. C. Khoo, "Role of ants in pest management," Annual Review of Entomology, vol. 37, pp. 479-503, 1992.

[7] R. Peng and K. Christian, "Integrated pest management in mango orchards in the Northern Territory Australia, using the weaver ant, Oecophylla smaragdina, (Hymenoptera: Formicidae) as a key element," International Journal of Pest Management, vol. 51, no. 2, pp. 149-155, 2005.

[8] G. R. DeFoliart, "Insects as food: why the western attitude is important," Annual Review of Entomology, vol. 44, pp. 21-50, 1999.

[9] J. Offenberg and D. Wiwatwitaya, "Sustainable weaver ant (Oecophylla smaragdina) farming: harvest yields and effects on 
worker ant density," Asian Myrmecology, vol. 3, no. 1, pp. 55-62, 2010.

[10] M. S. Barzman, N. J. Mills, and N. T. T. Cuc, "Traditional knowledge and rationale for weaver ant husbandry in the Mekong delta of Vietnam," Agriculture and Human Values, vol. 13, no. 4, pp. 2-9, 1996.

[11] R. K. Peng and K. Christian, "The dimpling bug, Campylomma austrina Malipatil (Hemiptera: Miridae): the damage and its relationship with ants in mango orchards in the Northern Territory of Australia," International Journal of Pest Management, vol. 54, no. 2, pp. 173-179, 2008.

[12] M. Sporleder and G. Rapp, "The effect of Oecophylla longinoda (Latr.) (Hym., Formicidae) on coconut palm productivity with respect to Pseudotheraptus wayi Brown (Hem., Coreidae) damage in Zanzibar," Journal of Applied Entomology, vol. 122, no. 8, pp. 475-481, 1998.

[13] R. Peng, M. G. Nielsen, J. Offenberg, and D. Birkmose, "Utilisation of multiple queens and pupae transplantation to boost early colony growth of weaver ants Oecophylla smaragdina," Asian Myrmecology, vol. 5, no. 1, pp. 177-184, 2013.

[14] D. Leston, "The ant mosaic-tropical tree crops and the limiting of pests and diseases," Tropical Pest Management, vol. 19, no. 3, pp. 311-341, 1973.

[15] C. Lokkers, Colony dynamics of the Green Tree Ant (Oecophylla smaragdina Fab.) in a seasonal climate [Ph.D. thesis], Department of Zoology, James Cook University of North Queensland, 1990.

[16] A. P. Gutierrez, Applied Population Ecology: A Supply-Demand Approach, John Wiley \& Sons, New York, NY, USA, 1996.

[17] J. Grangier and P. Lester, "Carbohydrate scarcity increases foraging activities and aggressiveness in the ant Prolasius advenus (Hymenoptera: Formicidae)," Ecological Entomology, vol. 39, no. 6, pp. 684-692, 2014.

[18] A. P. Gutierrez, "Analysis of biological control of cassava pests in Africa. II. Cassava mealybug Phenacoccus manihoti," Journal of Applied Ecology, vol. 25, no. 3, pp. 921-940, 1988.

[19] A. P. Gutierrez, J. S. Yaninek, B. Wermelinger, H. R. Herren, and C. K. Ellis, "Analysis of biological control of cassava pests in Africa. III. Cassava green mite Mononychellus tanajoa," Journal of Applied Ecology, vol. 25, no. 3, pp. 941-950, 1988.

[20] R. F. Denno, M. S. Mitter, G. A. Langellotto, C. Gratton, and D. L. Finke, "Interactions between a hunting spider and a webbuilder: consequences of intraguild predation and cannibalism for prey suppression," Ecological Entomology, vol. 29, no. 5, pp. 566-577, 2004.

[21] M. J. Crawley, Natural Enemies: The Population Biology of Predators, Parasites and Diseases, Blackwell Scientific Publications, 1992.

[22] J. M. Jeschke, M. Kopp, and R. Tollrian, "Predator functional responses: discriminating between handling and digesting prey," Ecological Monographs, vol. 72, no. 1, pp. 95-112, 2002.

[23] M. P. Hassell, J. H. Lawton, and J. R. Beddington, "Sigmoid functional responses by invertebrate predators and parasitoids," The Journal of Animal Ecology, vol. 46, no. 1, pp. 249-262, 1977.

[24] J. Mohaghegh, P. de Clercq, and L. Tirry, "Functional response of the predators Podisus maculiventris (Say) and Podisus nigrispinus (Dallas) (Het., Pentatomidae) to the beet armyworm, Spodoptera exigua (Hübner) (Lep., Noctuidae): effect of temperature," Journal of Applied Entomology, vol. 125, no. 3, pp. 131-134, 2001.
[25] L. D. B. Faria, J. Tuller, L. F. Maia, C. Reigada, and W. A. C. Godoy, "Alternative prey and abundance covariance switches an intraguild predator's functional response," Journal of Insect Behavior, vol. 27, no. 4, pp. 503-513, 2014.

[26] P. Schmid-Hempel, M. L. Winston, and R. C. Ydenberg, "Foraging of individual workers in relation to colony state in the social Hymenoptera," The Canadian Entomologist, vol. 125, no. 1, pp. 129-160, 1993.

[27] G. T. Lim, "Enhancing the weaver ant, Oecophylla smaragdina (Hymenoptera: Formicidae), for biological control of a shoot borer, Hypsipyla robusta (Lepidoptera: Pyralidae)," in Malaysian Mahogany Plantations, Department of Entomology, Virginia Polytechnic Institute and State University, Blacksburg, Va, USA, 2007.

[28] C. S. Holling, "The components of predation as revealed by a study of small-mammal predation of the european pine sawfly," The Canadian Entomologist, vol. 91, no. 5, pp. 293-320, 1959.

[29] A. J. Nicholson and V. A. Bailey, "The balance of animal populations," Proceedings of the Zoological Society of London, vol. 3, pp. 551-598, 1935.

[30] R. H. Crozier, P. S. Newey, E. A. Schlüns, and S. K. A. Robson, "A masterpiece of evolution Oecophylla weaver ants (Hymenoptera: Formicidae)," Myrmecological News, vol. 13, pp. 57-71, 2009.

[31] C. R. Carroll and D. H. Janzen, "Ecology of foraging by ants," Annual Review of Ecology and Systematics, vol. 4, no. 1, pp. 231257,1973

[32] S. J. Risch and C. R. Carroll, "The ecological role of ants in two Mexican agroecosystems," Oecologia, vol. 55, no. 1, pp. 114-119, 1982.

[33] N. Rastogi, "Prey concealment and spatiotemporal patrolling behaviour of the Indian tree ant Oecophylla smaragdina (Fabricius)," Insectes Sociaux, vol. 47, no. 1, pp. 92-93, 2000.

[34] J. Wojtusiak, E. J. Godzińska, and A. Dejean, "Capture and retrieval of very large prey by workers of the African weaver ant, Oecophylla longinoda (Latreille 1802)," Tropical Zoology, vol. 8, no. 2, pp. 309-318, 1995.

[35] B. Hölldobler, "Territorial behavior in the green tree ant (Oecophylla smaragdina)," Biotropica, vol. 15, no. 4, pp. 241-250, 1983.

[36] A. J. Baettie, The Evolutionary Ecology of Ant-Aphid Mutualisms, Cambridge University Press, 1985.

[37] B. Hölldobler and E. O. Wilson, The Ants, Springer, Berlin, Germany, 1990.

[38] M. Chapuisat and L. Keller, "Division of labour influences the rate of ageing in weaver ant workers," Proceedings of the Royal Society of London, Series B: Biological, vol. 269, no. 1494, pp. 909-913, 2002.

[39] B. Gobin and F. Ito, "Queens and major workers of Acanthomyrmex ferox redistribute nutrients with trophic eggs," Naturwissenschaften, vol. 87, no. 7, pp. 323-326, 2000.

[40] A. A. Smith, B. Hölldobler, and J. Liebig, "Hydrocarbon signals explain the pattern of worker and egg policing in the ant Aphaenogaster cockerelli," Journal of Chemical Ecology, vol. 34, no. 10, pp. 1275-1282, 2008.

[41] A. Sih and M. S. Baltus, "Patch size, pollinator behaviour, and pollinator limitation in catnip." Ecology, vol. 68, no. 6, pp. 16791690, 1987.

[42] B. Hölldobler and E. O. Wilson, The Superorganism. The Beauty, Elegance, and Strangeness of Insect Societies, W.W. Norton and Company, New York, NY, USA, 2009. 

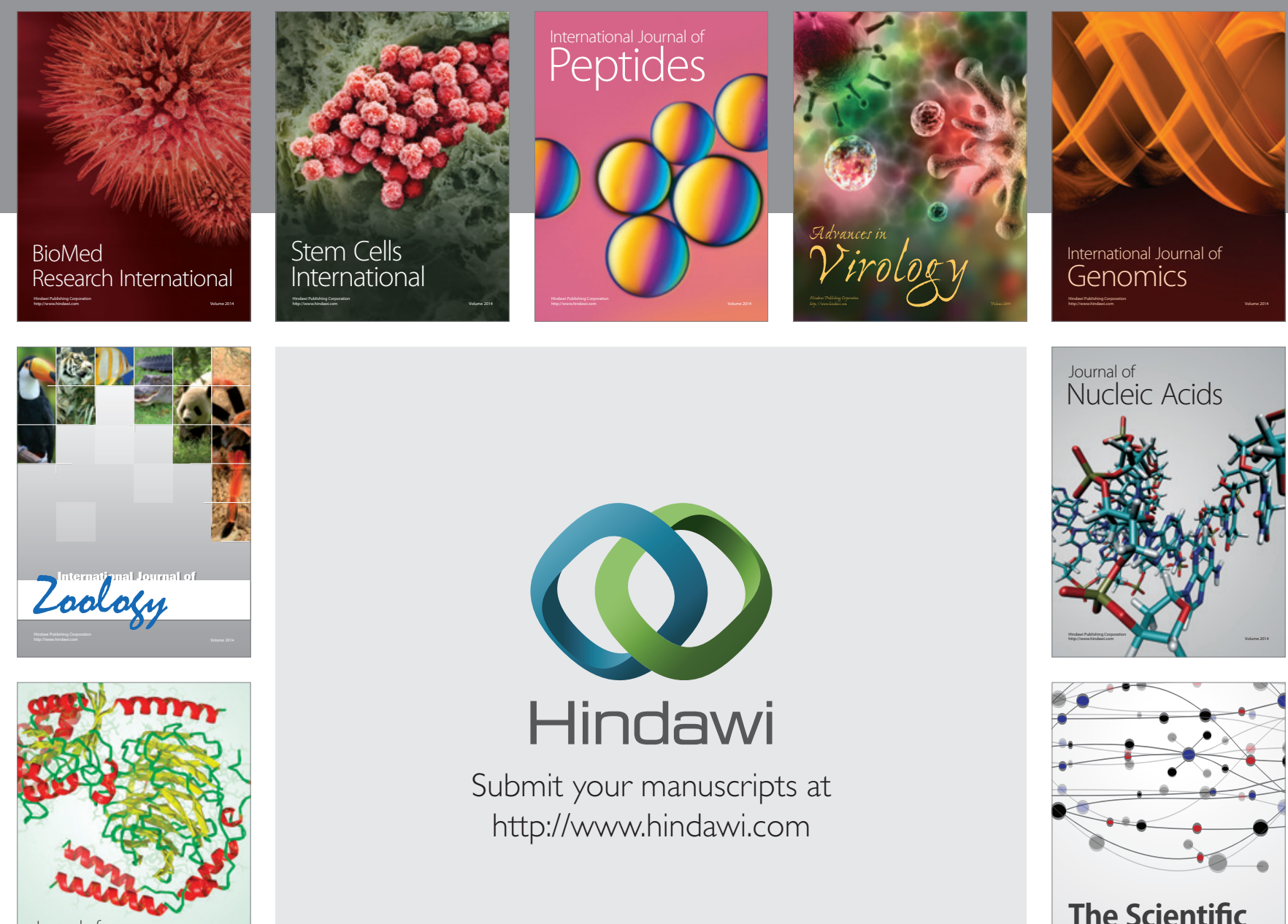

Submit your manuscripts at

http://www.hindawi.com

Journal of
Signal Transduction
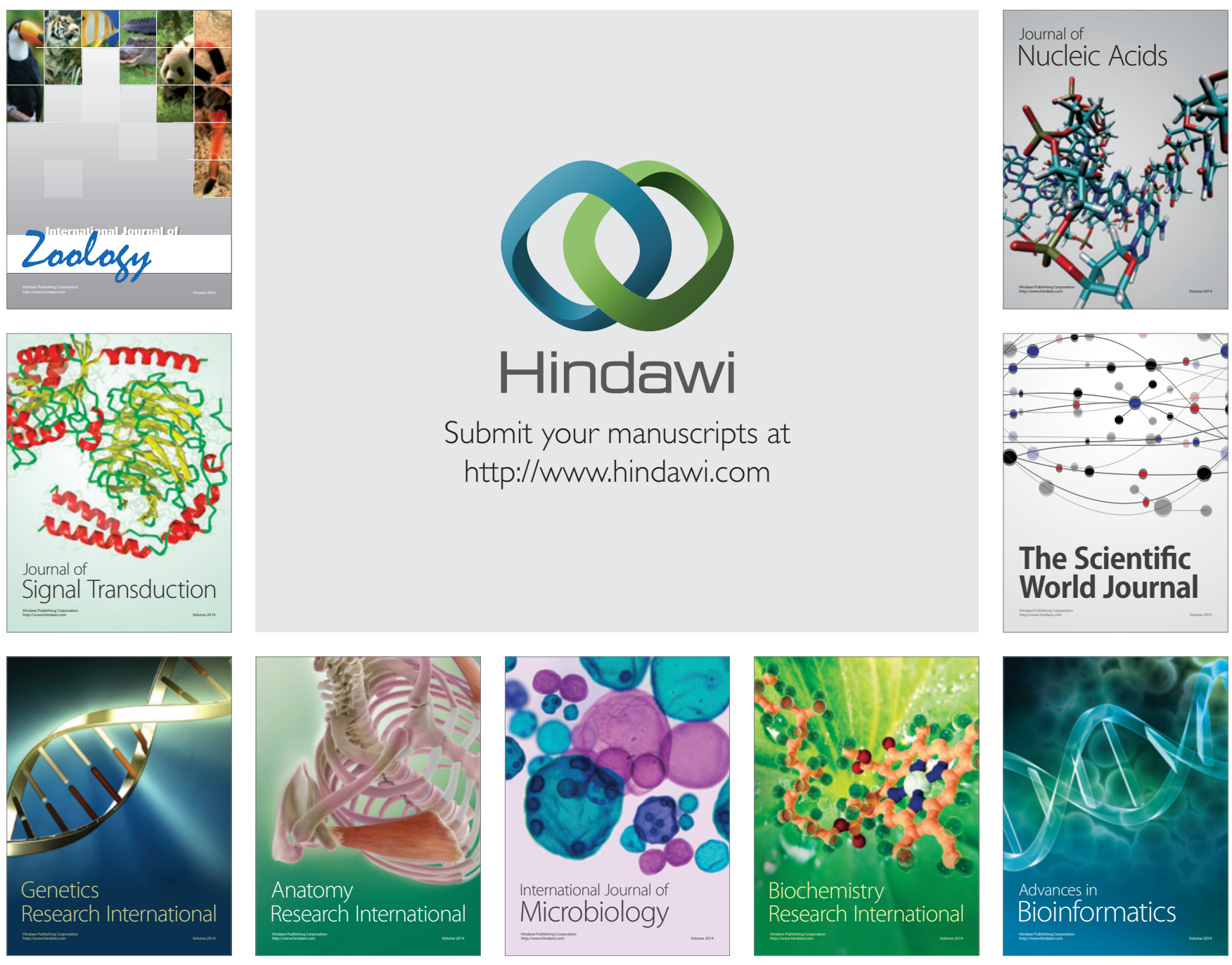

The Scientific World Journal
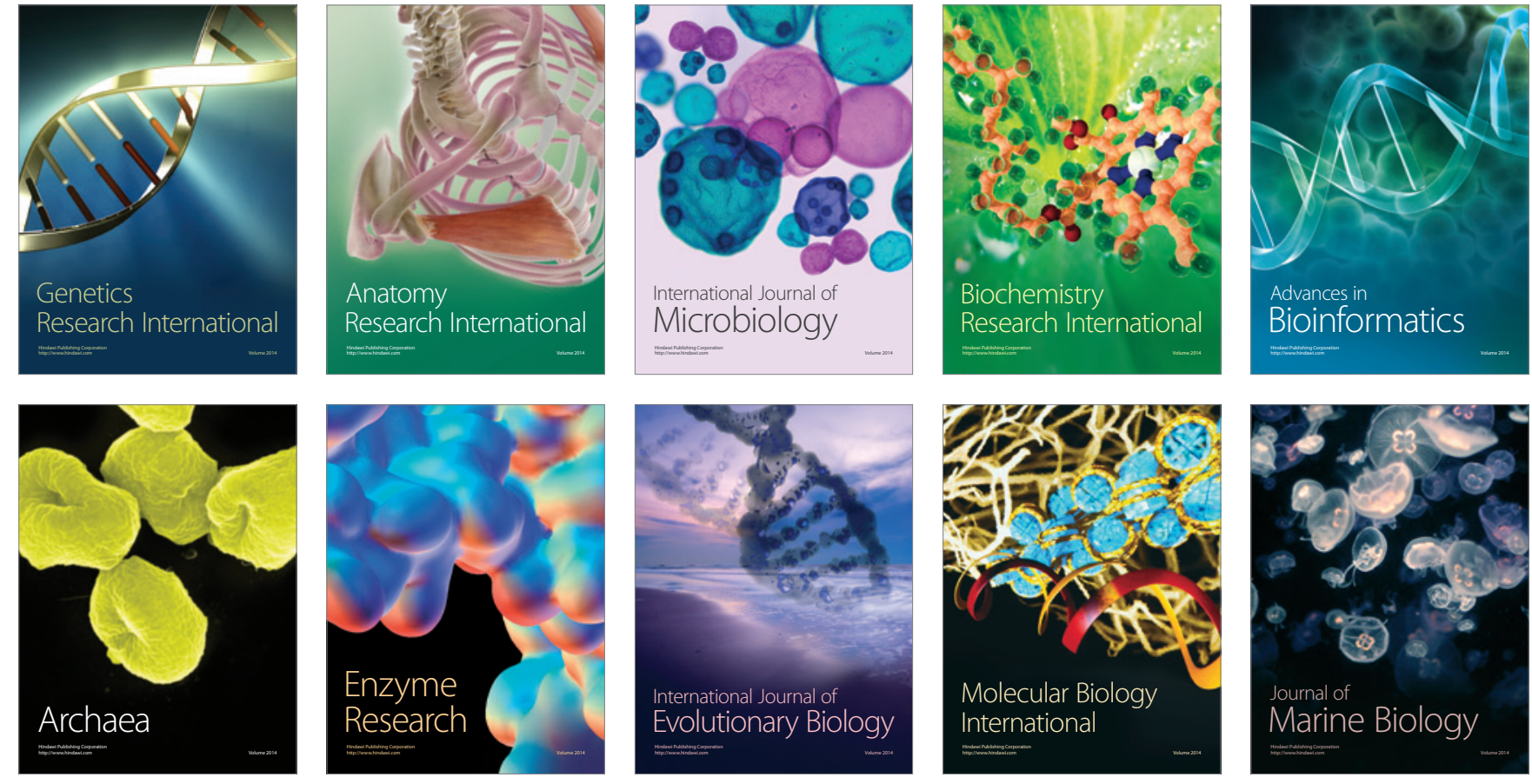